\title{
Endo-Helminth Fauna of the Rainbow Lizard (Agama Agama)
}

\section{Belema Robert $^{1}$, Nioking Amadi ${ }^{2}$, Chidinma Charity Amuzie ${ }^{1}$, Adaobi Patricia Ugbomeh ${ }^{3}$}

${ }^{1}$ Entomology and Parasitology Laboratory, Department of Animal and Environmental Biology, Rivers State University, Port Harcourt, Nigeria. ${ }^{2}$ Wildlife and Conservation Group, Department of Animal and Environmental Biology, Rivers State University, Port Harcourt, Nigeria. ${ }^{3}$ Hydrobiology/Ecotoxicology Unit, Department of Animal and Enviroanmental Biology, Rivers State University, Port Harcourt, Nigeria

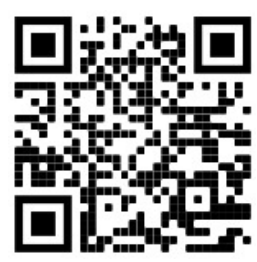

*Corresponding Author: Belema Robert

Email: robertbelema40@gmail.com

Article Info

Article history:

Received 7 July 2020

Received in revised form 16 July 2020

Accepted 19 July 2020

Keywords:

Helminths

Parasites

Agama agama

Niger Delta

\begin{abstract}
This parasitological study was carried out between February and May 2019 to determine the prevalence and intensity of helminthiasis in the rainbow lizard (Agama agama) in Okrika, Rivers State, Nigeria. A total of one hundred and fifty-one (151) specimens made up of 93 males and 75 females were caught by a local netting system during the day and anaesthesized with chloroform. Samples were collected from two stations (Ogoloma-Ama and Oba-Ama). After dissection, the esophagus, stomach, small intestine, rectum, liver, lungs, urinary bladder, heart and body cavity were searched for helminths using conventional methods. Five species of helminths belonging to Nematoda - Strongyluris brevicaudata, Parapharyngodon awokoyai, encysted Ascaridida larva, Cestoda - Oochoristica sp. and Trematoda Mesocoelium spp - were recovered from infected lizards. Helminths infected one hundred and twenty-three (123) (82\%) of the lizards. In Oba-Ama, forty-five (45) (76.3\%) out of 59 and in Ogoloma-Ama, seventy-eight (78) (84.8\%) out of 92 were infected with helminths. By abundance, in both locations, the males were more infected than their female counterparts with a prevalence of $51(93 \%)$ and $72(75 \%)$ $(P<0.05)$, respectively. This study has revealed the helminth parasites infecting the agamid lizard of Rivers State, Nigeria. It has also shown some unidentified species of Mesocoelium and Oochoristica sp. Additionally the trapping system used was also found to be effective and efficient.
\end{abstract}

\section{Introduction}

Lizards are seen in most warm places around the world as a result of their nature as poikilotherms (Omonona et al., 2011). They are about the most numerous extant species of reptiles, with over 4300 members (Benneth, 1998). They vary in their sizes, morphologies and colors. They exhibit various means of movement and defense. In Africa, commonly found lizards are the geckos, chameleons, monitor lizards, skinks, alligators, crocodiles and the Agama lizards (Benneth, 1998). The Agama is a typical member of the Agamidae family seen abundantly in Africa, Asia, Australia, and sighted in Southeastern Europe by Benneth (1998).

The agamid lizard is diurnal in nature residing in crevices at night close to habitations (Harris, 1964) though it has been reported just recently to have become active at night feeding off on insects and resting on warm walls having electric panels reasons for which 
could be increased predation due to rapid expansion of the urban environment and thermoregulation at night (Amadi et al., 2020).

Helminths are mostly parasites of vertebrates but could also be found in invertebrates, specifically arthropods and mollusks, which serve as intermediate hosts (Smyth, 1994). Parasites are very important causes of high death rates in wild animal populations (Anderson and Gordon, 2009).

In Nigeria, the investigations of Babero \& Okpala (1962) and Wekhe \& Olayinka (1999) revealed the parasite Lecudina sp., a gregarinid protozoan which is pathogenic and poses human health risks and uses the Rainbow lizard as its intermediate host. According to Ameh \& Ajayi (1996), man could also be exposed to Lecudina infection by termite consumption due to the presence of this protozoan in the gut of termites. Another helminth parasite, Raillietiella sp. (a pentastomid) is also frequently isolated from lizards (Nash, 2005).

The aim of this study is to identify the helminth endoparasites of Agama agama in OgolomaAma and Oba-Ama of Okrika, Rivers State, and to determine the intensity and prevalence of the helminth endoparasites of A. agama in both locations while also investigating any relationship between the snout-vent length (SVL) and body weight (WT) of the lizards, and parasite burden.

\section{Methods}

\section{Study Area}

Okrika is an island between Latitudes $4^{\circ} 44^{\prime} 31.74 " \mathrm{~N}$ and Longitude $7^{\circ} 05^{\prime} 1.25^{\prime \prime} \mathrm{E}$ while Ogoloma Ama and Oba Ama are settlements (Fig 1) on the island between latitudes $4^{\circ} 73^{\prime}$ 38.76" N, $4^{\circ} 77^{\prime} 35.71 " \mathrm{~N}$ and Longitude $7^{\circ} 08^{\prime} 11.03 " \mathrm{E}$ and $7^{\circ} 07^{\prime}$ 82.41."E respectively, in Rivers State, Eastern Niger Delta, Nigeria, it is a tropical region with the river system been an estuary with tidal movements. the rainy season is from April to September with a break in August though it lasted longer till about December in 2018-2019. Okrika has temperatures ranging from $260 \mathrm{C}$ to $34^{\circ} \mathrm{C}$.

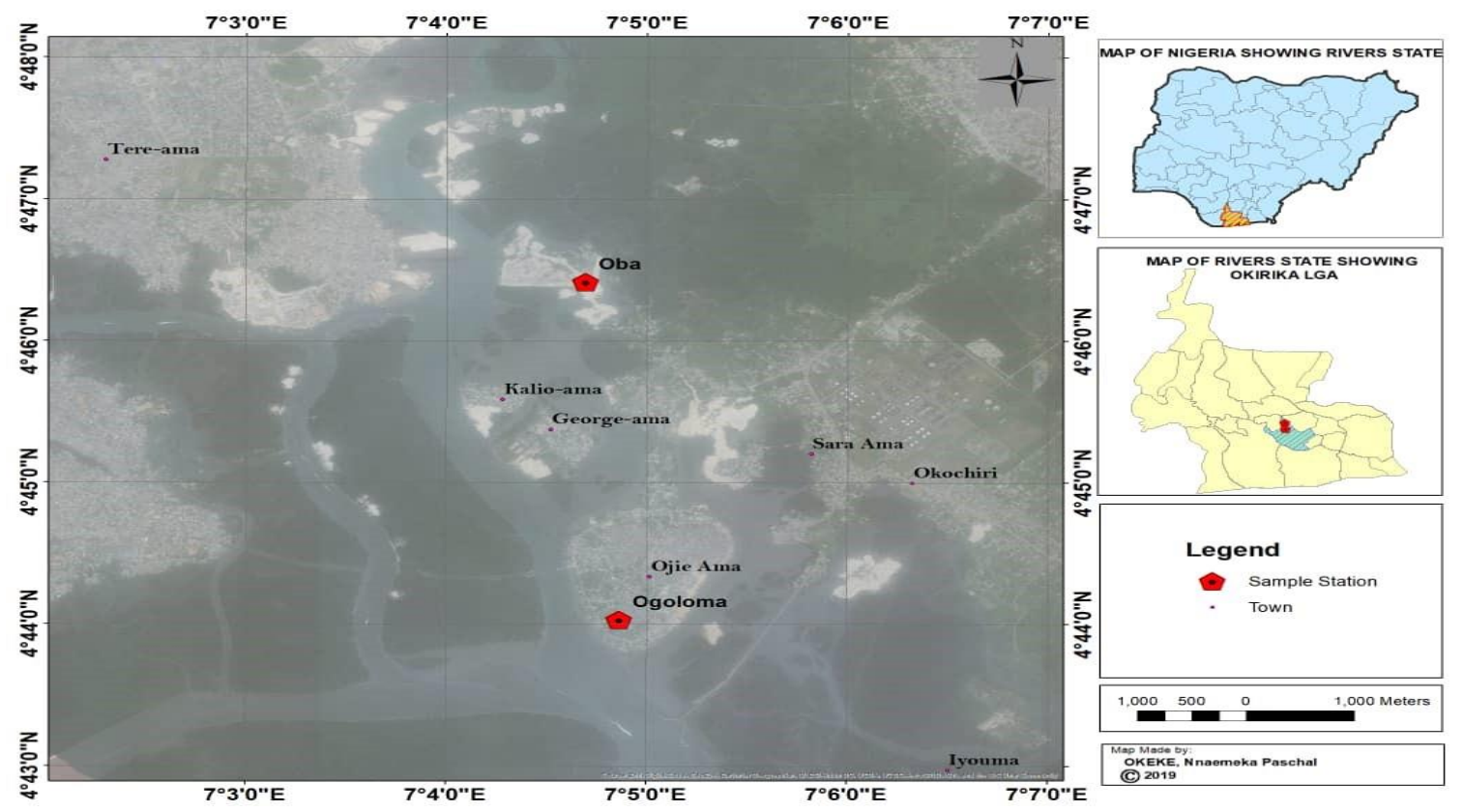

Figure 1. Map of study area showing sample stations 


\section{Sample collection}

One hundred and fifty-one (151) Agama agama were randomly captured by trapping during the day near residential buildings (between 7am and 4pm) from February to May, 2019. The trap used was made up of four wooden pecks of $24 \mathrm{~cm} \times 2 \mathrm{~cm}$ set in alternate positions in the ground forming a square around residential buildings where lizards were sighted. The pegs were covered with a nylon net of mesh size $2 \mathrm{~cm} / 20 \mathrm{~mm}$ as shown in Fig 2 and Plate 1. A $100 \mathrm{~g}$ weight was used to keep the edges in place. A local bait made from grinded and dried cassava (Manihot esculenta) and palm oil was placed in the middle of the trap. The bait attracted insects which attracted the lizards. Lizards were trapped when they entered the net to feed on the insects. Specimens were removed from the trap and transported to the Entomology and Parasitology Laboratory, Rivers State University, Port Harcourt, in buckets covered with a net to allow ventilation. Specimens were anaesthesized with chloroform and dissected.

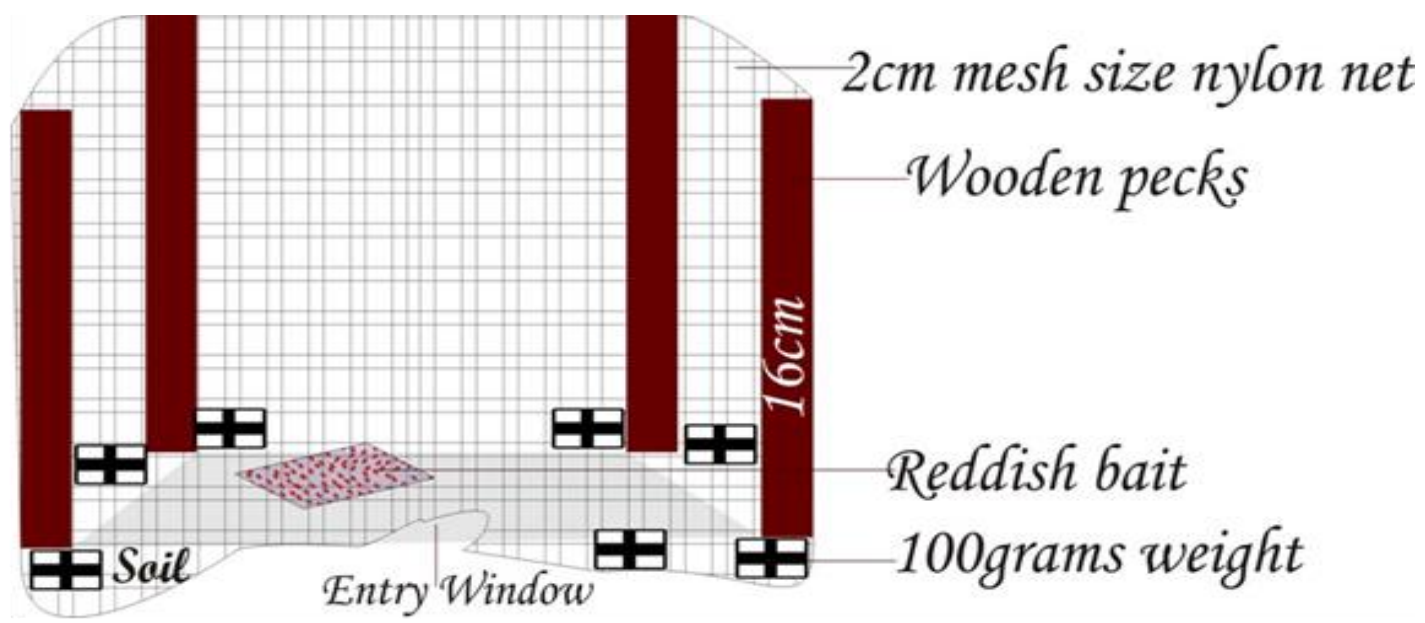

Figure 2. Outlook of the local netting for lizard sampling

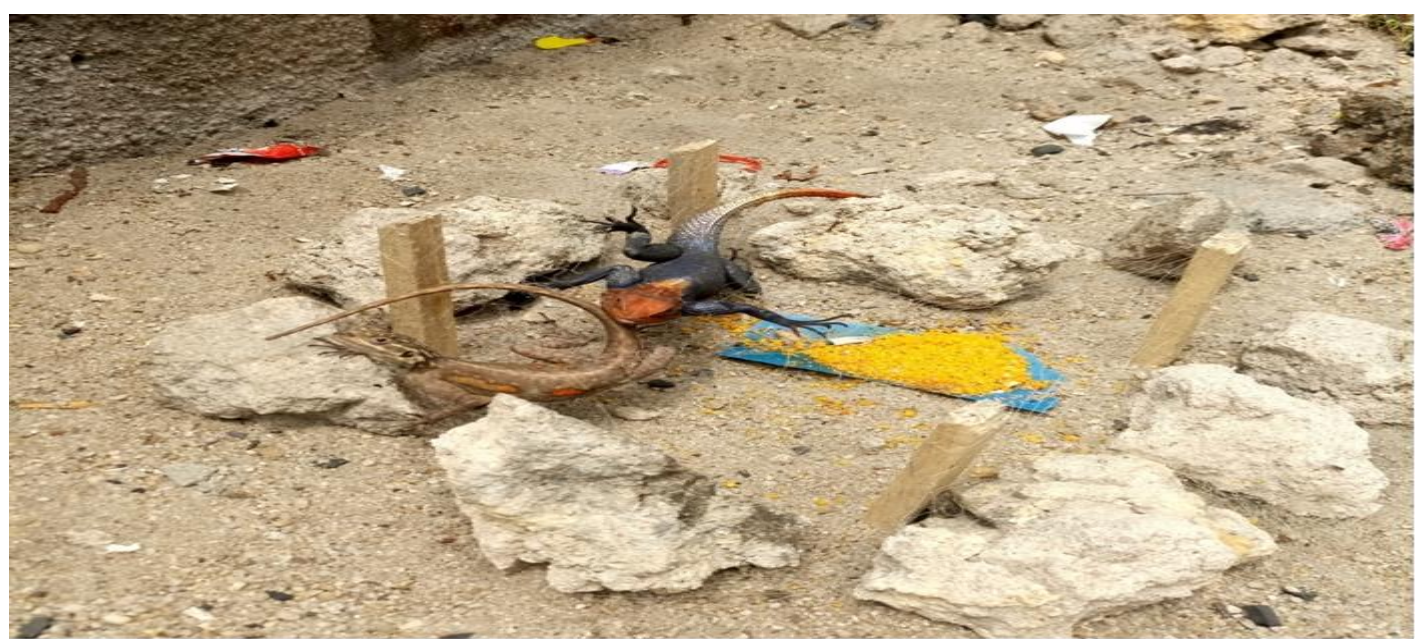

Figure 3. A trap showing a successful catch at Oba Ama, Okrika LGA, Rivers State, Nigeria 


\section{Dissection of Specimens}

The lizards were anaesthesized by exposure to chloroform vapor in an airtight container. Each individual lizard was weighed with Adams electronic weighing balance (model AQP 1600). The Snout vent length (SVL) was taken by the aid of a measuring board and a transparent meter rule. The ventral surface was longitudinally cut open by making an incision from the vent to the throat of each lizard. The gastrointestinal tract (GIT) was recovered by cutting the anterior of the oesophagus and the posterior end of the rectum. The body cavity and internal organs (liver, lungs, urinary bladder and heart) were properly examined separately in Petri dishes containing $0.72 \%$ saline solution for the presence of motile and adhering helminth parasites with the aid of a dissecting microscope. The skin was carefully removed exposing the subcutaneous layers which were examined for the presence of microfilaria. Recovered parasites were washed in the $0.72 \%$ saline solution to remove debris and mucus and ensure proper preservation.

\section{Fixing and Staining of Helminth Parasites}

Nematodes recovered were stretched in hot $70 \%$ alcohol and later fixed in fresh cold $70 \%$ alcohol. Few drops of glycerol were added to reduce total dehydration of the nematode. Nematodes were cleared in lactophenol before microscopy. Cestodes and trematodes were flattened in 5\% formol saline by placing them between two microscope slides for about 15 minutes. Thereafter, they were washed in several changes of distilled water to remove the excess fixative used, stained overnight in acetocarmine and dehydrated within $24 \mathrm{~h}$ in series of graded alcohol $(30 \%, 50 \%, 70 \%$ and $100 \%)$ at intervals of $1 \mathrm{~h}$. They were then cleared in a solution of 50/50\% alcohol and xylene and in absolute xylene, mounted in Canada balsam for permanent slides, and examined under a Compound microscope using a x10 objective.

Helminths were identified according to protocols of Yamaguti (1958) and Schmidt (1986). The number of helminth parasites recovered was recorded per location in the gut. Photomicrographs of representative helminth species were made using a Nikon Digital Camera attached to the eye piece of the light microscope.

\section{Statistical Analyses}

Student t-test was used to check for significant difference in the prevalence of parasite infection between sexes and locations. Chi-square was used to test for associations between parasite prevalence by sexes and locations. Analysis of variance was used to test for significant difference between parts of the GIT and Tukey-Kramer test was used for mean separation. Pearson correlations were used to test for relationships between selected variables. These Analyses were done using JMP-SAS package.

\section{Results and Discussion}

\section{Abundance and Total Prevalence of Helminth Parasites in both Locations} One hundred and fifty-one (151) lizards were examined in the course of the research; fiftynine (59) were from Oba-Ama and ninety-two (92) from Ogoloma-Ama. The hosts from Oba-Ama were comprised of twenty-one (21) males and thirty-eight (38) females, while those from Ogoloma-Ama were thirty-four (34) males and fifty-eight (58) females. Overall, one hundred and twenty-three (123) lizards were infected accounting for a total prevalence of $82 \%$. By location, out of 59 hosts, 45 were infected at Oba-Ama with a prevalence of $76.3 \%$, while 78 out of the 92 hosts from Ogoloma-Ama were also infected accounting for a prevalence of $84.8 \%$. Total parasites recovered from these hosts numbered 2,446: 788 from 
Oba-Ama and 1, 658 from Ogoloma-Ama. There was, statistically, no difference between the parasite load of both locations $\left(\mathrm{t}_{1}=2.7682, \mathrm{p}=0.0983\right)$.

The parasites recovered included cestodes (Oochoristica sp.), trematodes (Mesocoelium spp) and nematodes (encysted Ascaridida larva, Parapharyngodon awokoyai and Strongyluris brevicaudata) (Plates 2-5). The prevalence and mean intensity of infection by these parasites are presented in Table 1.

Table 1. Prevalence (P\%) and mean intensity (MI) of helminth parasite infection in Agama agama, Okrika, Rivers State, Nigeria

\begin{tabular}{|c|c|c|c|c|}
\hline \multirow[t]{3}{*}{ Parasite } & \multicolumn{4}{|c|}{ Location } \\
\hline & \multicolumn{2}{|c|}{ Oba-Ama } & \multicolumn{2}{|c|}{ Ogoloma-Ama } \\
\hline & $\mathrm{P} \%$ & $\mathrm{MI} \pm \mathrm{SD}$ & $\mathrm{P} \%$ & $\mathrm{MI} \pm \mathrm{SD}$ \\
\hline \multicolumn{5}{|l|}{ Cestoda } \\
\hline Oochoristica sp & 5 & $2.64 \pm 1.8$ & 4 & $1.92 \pm 1.3$ \\
\hline \multicolumn{5}{|l|}{ Trematoda } \\
\hline Mesocoelium sp. & 14 & $27.75 \pm 13.1$ & 6 & $15.00 \pm 9.2$ \\
\hline \multicolumn{5}{|l|}{ Nematoda } \\
\hline $\begin{array}{l}\text { Encysted ascaridida } \\
\text { larva }\end{array}$ & 1 & $1.00 \pm 0.0$ & 2 & $1.88 \pm 0.9$ \\
\hline $\begin{array}{l}\text { Parapharyngodon } \\
\text { awokoyai }\end{array}$ & 31 & $7.09 \pm 4.6$ & 36 & $8.88 \pm 6.9$ \\
\hline $\begin{array}{l}\text { Strongyluris } \\
\text { brevicaudata }\end{array}$ & 50 & $8.59 \pm 7.7$ & 51 & $11.28 \pm 9.3$ \\
\hline
\end{tabular}

\section{Gender influence on Prevalence of Parasites}

Nematodes were more prevalent than both cestodes and trematodes and higher values were obtained in male hosts than in their female counterparts (Table 2). For instance, in hosts from Ogoloma Ama, nematodes infected $94 \%$ of the male hosts and $79 \%$ of the females. Similarly, higher prevalence of infection was recorded in hosts from Ogoloma-Ama. Similarly, nematodes infected $91 \%$ of the male hosts and $71 \%$ of the females in Oba-Ama. However, student $t$-tests showed the differences were not statistically significant $\left(t_{1}=2.768, p=0.098\right)$. Generally, in Okrika, the male hosts were more infected. Student-t tests showed that there was a statistical difference between the male and female hosts $\left(t_{1}=26.25, \mathrm{p}=0.0001\right)$.

Table 2. Total prevalence (P\%) and mean intensity (MI) of classes of helminth parasites in male and female lizards (A. agama) of Ogoloma-Ama and Oba-Ama, Okrika LGA, Rivers State, Nigeria

\begin{tabular}{|c|c|c|c|c|}
\hline \multirow{2}{*}{ Parasite } & \multicolumn{2}{|c|}{ Ogoloma-Ama } & \multicolumn{2}{c|}{ Oba-Ama } \\
\cline { 2 - 5 } & Male & Female & Male & Female \\
\hline
\end{tabular}




\begin{tabular}{|l|c|c|c|c|c|c|c|c|}
\hline & $\mathbf{P \%}$ & $\mathbf{M I} \pm \mathbf{S D}$ & $\mathbf{P \%}$ & $\mathbf{M I} \pm \mathbf{S D}$ & $\mathbf{P \%}$ & $\mathbf{M I} \pm \mathbf{S D}$ & $\mathbf{P \%}$ & $\mathbf{M I} \pm \mathbf{S D}$ \\
\hline Nematode & 94 & $24.6 \pm 18.6$ & 79 & $12 \pm 11$ & 91 & $20.8 \pm 16.7$ & 71 & $8.8 \pm 12.5$ \\
\hline Cestode & 62 & $2.2 \pm 1.5$ & 28 & $1.5 \pm 0.6$ & 48 & $1.4 \pm 1.9$ & 11 & $0.2 \pm 0.7$ \\
\hline Trematode & 12 & $15.5 \pm 10.1$ & 5 & $14.3 \pm 7.6$ & 19 & $1.9 \pm 3.9$ & 0 & $0.0 \pm 0.0$ \\
\hline
\end{tabular}

\section{Site Preference of Parasitic Helminth Species of Agama agama}

The rectum and the small intestine had the highest abundance and infection rates, respectively (Tables 3- 4). In hosts from Oba-Ama, a total of 395 individulas of Strongyluris brevicaudata were recovered from the specimens- $359(91 \%)$ and $36(9 \%)$ from the rectum and small intestine, respectively. 241(100\%) Parapharyngodon awokoyai were only found in the rectum. 71(64\%) and 40(36\%) of Mesoceolium spp were recovered from the rectum and small intestine, respectively. 37(100\%) Oochoristica sp. was recovered from the small intestine and 4(100\%) Ascaridida larva were encysted on the body cavity. In Ogoloma-Ama, the rectum and the small intestines were the most infected sites too (Table 4). 808 (96\%) Strongyluris brevicaudata were recovered from the rectum, 28(3\%) from the small intestine and 10(1\%) from the body cavity. 604 (100\%) Parapharyngodon awokoyai were only recovered from the rectum. (100\%) Mesocoelium spp were recovered from the rectum, 71(100\%) Oochoristica sp. from the small intestine and 32(100\%) Ascaridida larva were seen encysted in the body cavity.

Table 3. Site preference of helminth endoparasites in A. agama from Oba-Ama, Okrika, Rivers State, Nigeria

\begin{tabular}{|l|c|c|c|c|}
\hline \multirow{2}{*}{ Parasite } & \multirow{2}{*}{$\begin{array}{c}\text { Parasite } \\
\text { Abundance }\end{array}$} & \multicolumn{3}{|c|}{ Distribution } \\
\cline { 3 - 5 } & & $(\mathrm{BC})$ & $(\mathrm{RC})$ & $(\mathrm{SI})$ \\
\hline S. brevicaudata & 395 & $0(0 \%)$ & $359(91 \%)$ & $36(9 \%)$ \\
\hline P. awokoyai & 241 & $0(0 \%)$ & $241(100 \%)$ & $0(0 \%)$ \\
\hline Mesoceolium spp & & & & \\
\hline Oochoristica sp. & 111 & $0(0 \%)$ & $71(64 \%)$ & $40(36 \%)$ \\
\hline Encysted Ascaridida larva & 37 & $0(0 \%)$ & $0(0 \%)$ & $37(100 \%)$ \\
\hline
\end{tabular}

Key: RC= Rectum; SI= Small Intestine; $\mathrm{BC}=$ Body Cavity

Table 4. Site preference of helminth endoparasites in A. agama from Ogoloma-Ama, Okrika, Rivers State, Nigeria

\begin{tabular}{|l|l|l|}
\hline Parasite Ogoloma & Abundance & Distribution \\
\hline
\end{tabular}




\begin{tabular}{|l|c|c|c|c|}
\hline & & $\mathrm{BC}$ & $\mathrm{RC}$ & $\mathrm{SI}$ \\
\hline S. brevicaudata & 846 & $10(1 \%)$ & $808(96 \%)$ & $28(3 \%)$ \\
\hline P. awokoyai & 604 & $0(0 \%)$ & $604(100 \%)$ & $0(0 \%)$ \\
\hline Mesocoelium spp. & 105 & $0(0 \%)$ & $105(100 \%)$ & $0(0 \%)$ \\
\hline Oochoristica sp & 71 & $0(0 \%)$ & $0(0 \%)$ & $71(100 \%)$ \\
\hline Encysted Ascaridida larva & 32 & $100 \%$ & $0(0 \%)$ & $0(0 \%)$ \\
\hline
\end{tabular}

Key: RC= Rectum; SI= Small Intestine; $\mathrm{BC}=$ Body Cavity
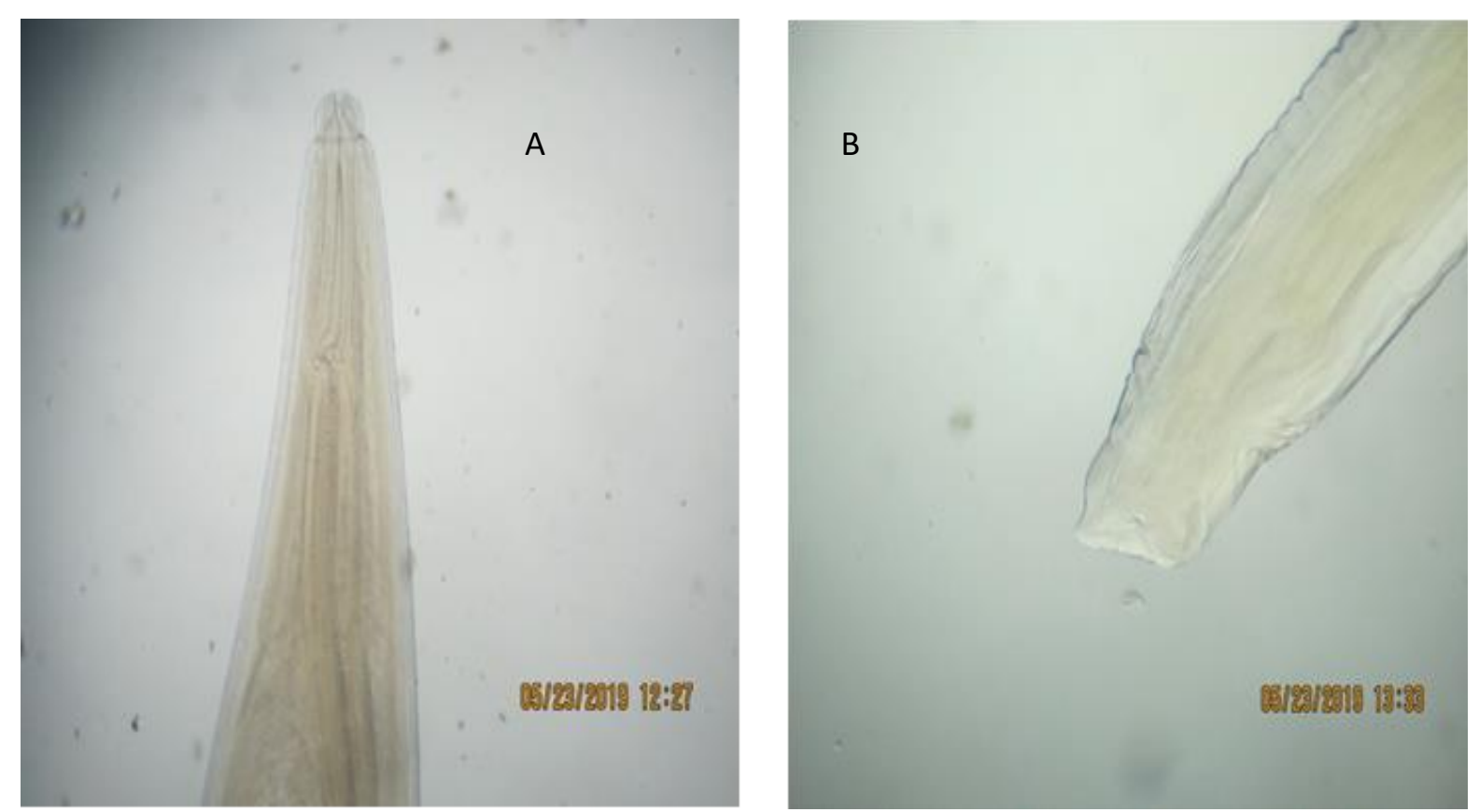

Figure 4. Photomicrographs of Parapharyngodon awokoyai recovered from Agama agama in Okrika, Rivers State, Nigeria. A(anterior) and B(posterior). Scale: $0.5 \mathrm{~mm}$ 


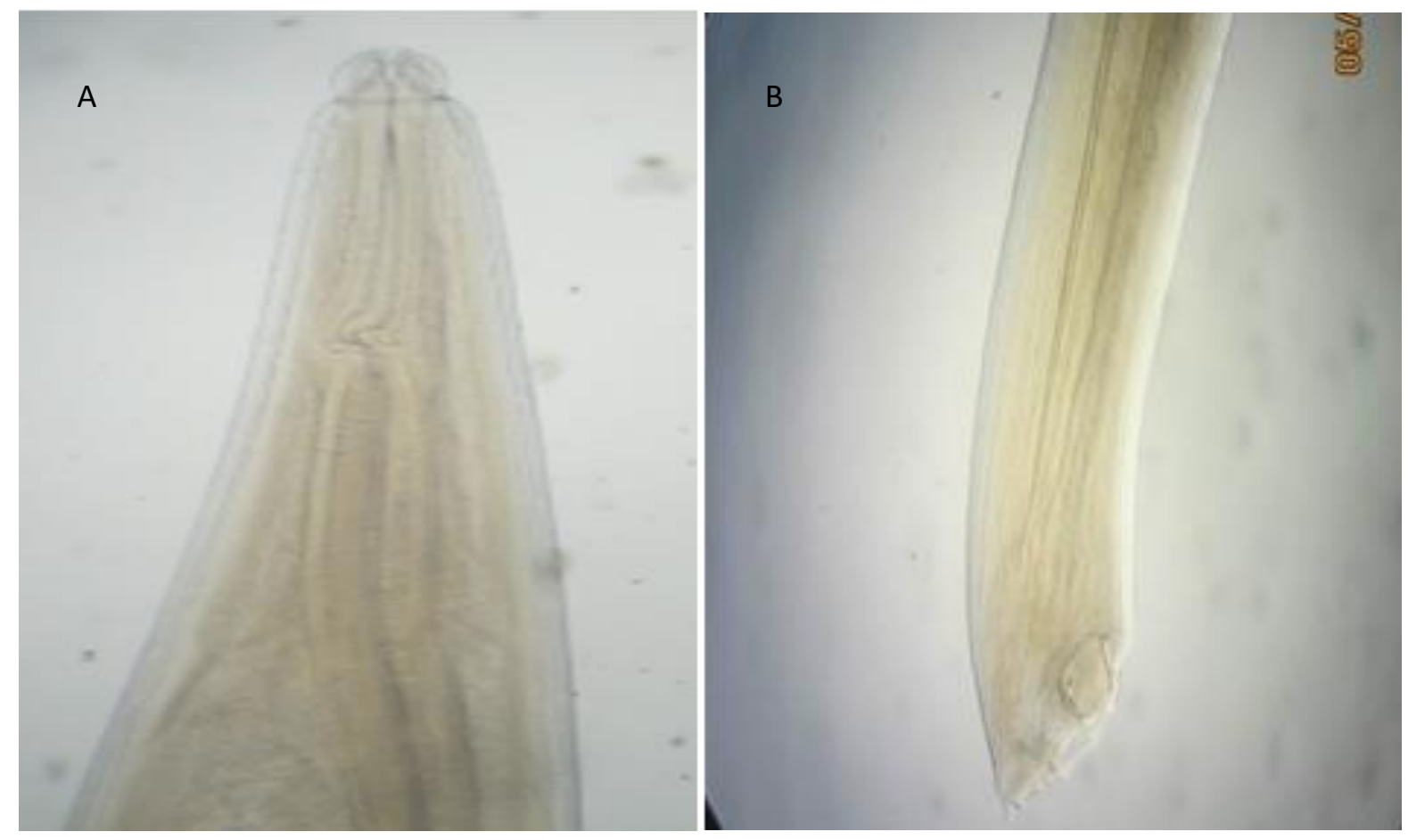

Figure 5. Photomicrographs of Strongyluris brevicaudata recovered from Agama agama in Okrika, Rivers State, Nigeria. A(anterior) and B(posterior). Scale: $0.5 \mathrm{~mm}$
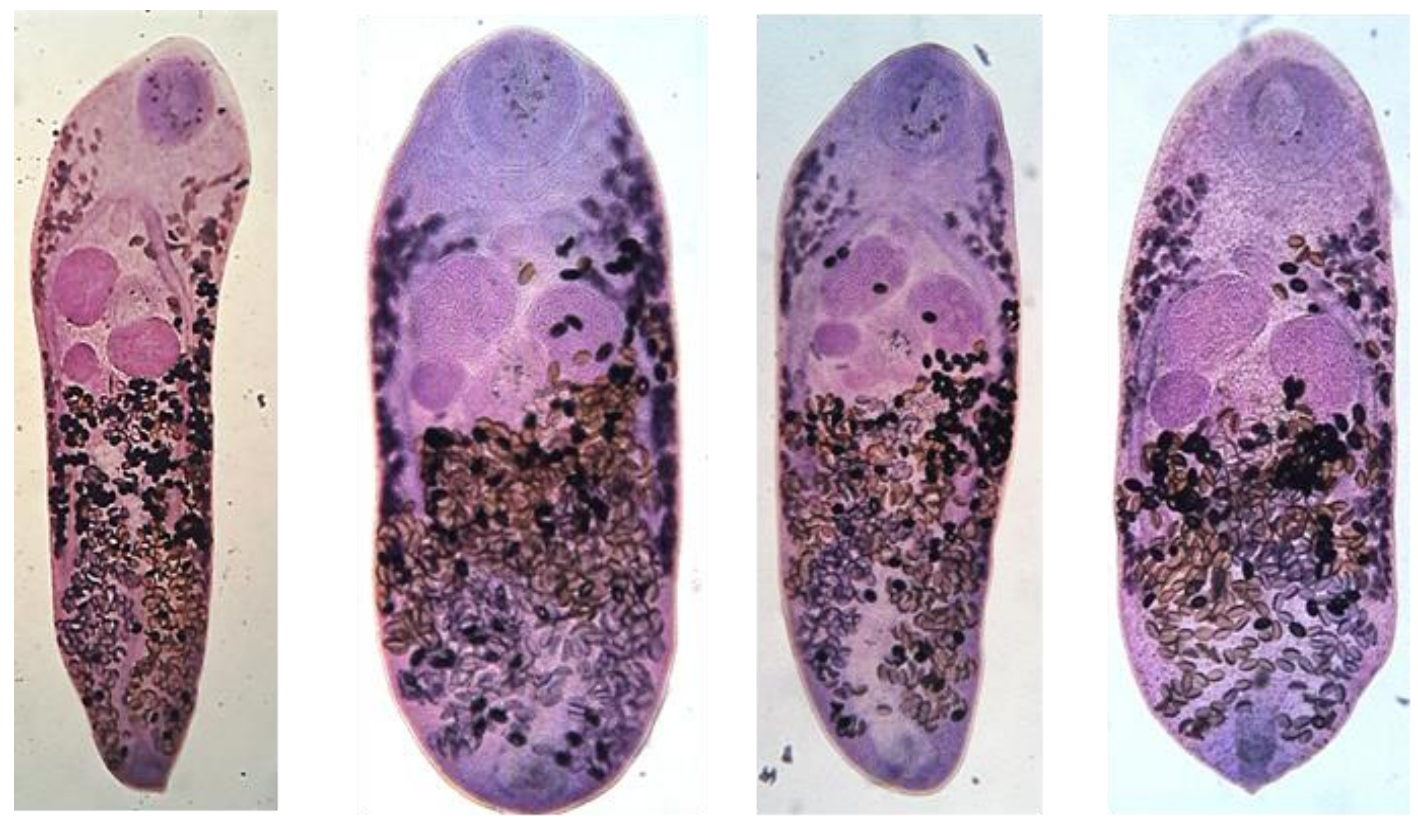

Figure 6. Photomicrographs of Mesoceolium spp recovered from Agama agama in Okrika, Rivers State, Nigeria 

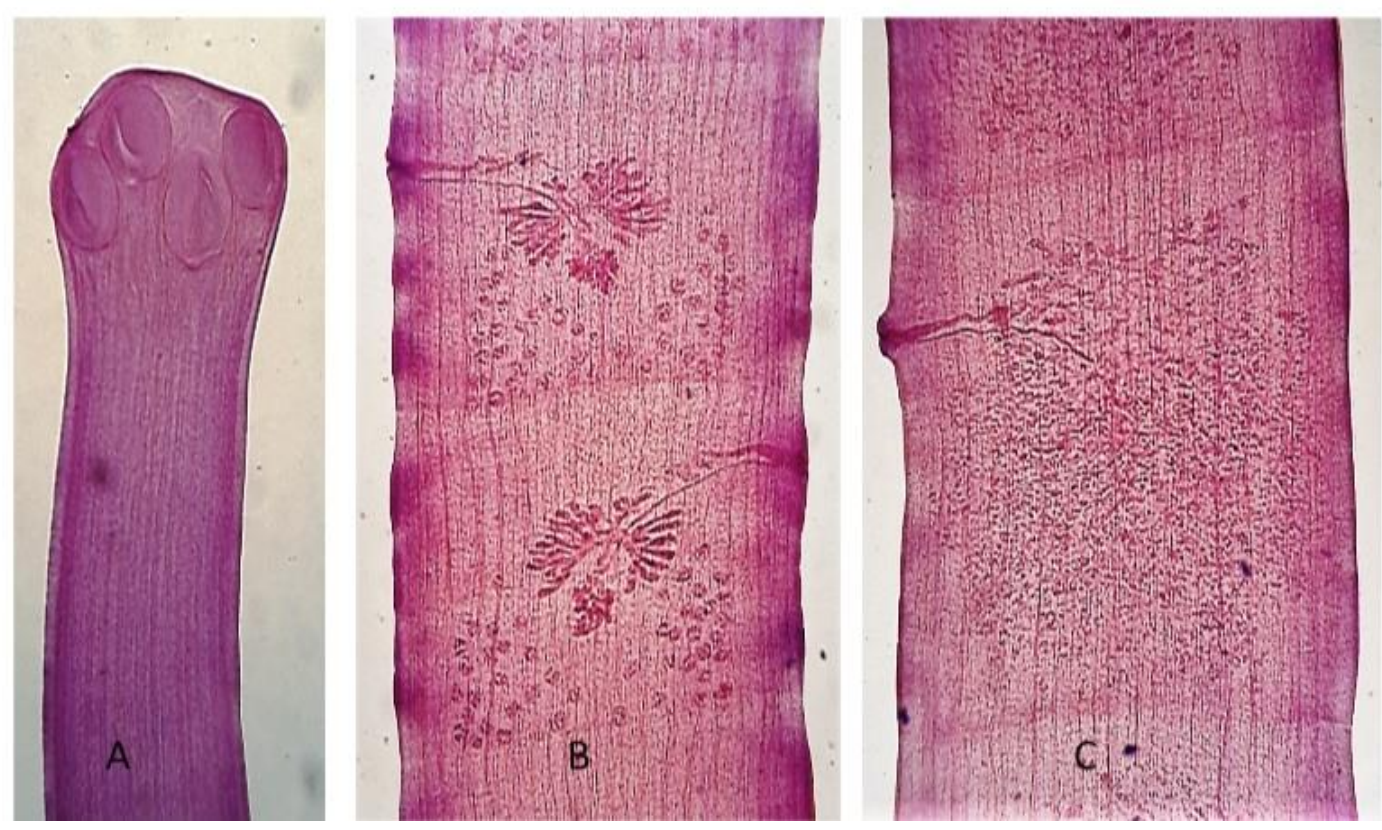

Figure 7. Photomicrographs of Oochoristica sp. recovered from Agama agama of Okrika, Rivers State, Nigeria

Five helminth species were isolated from the rainbow lizard (Agama agama) in this study and they included Strongyluris brevicaudata, Parapharyngodon awokoyai, encysted Ascaridida larva, Mesocoelium spp and Oochoristica sp. Some of these helminths observed have been reported previously from similar studies in Nigeria. Babero \& Okpala (1962) and Adeoye \& Ogunbanwo (2007) reported Strongyluris brevicaudata, Parapharyngodon awokoyai, Capillaria sp, Oxyuris sp, Oochoristica agamae, Mesocoelium monas and Railiettiella sp. from Lagos and Osun States, respectively. In their own research, Omonona et al. (2011) recovered Strongyluris brevicaudata and Thelandros annulatus from same host in Lagos. These reports show that these helminths have a wide geographical distribution. The environmental factors of all the locations could be said to be alike therefore equally supporting the existence of these parasites.

The overall prevalence ( $82 \%$ ) recorded in this investigation is same with the $82 \%$ recorded by Zazoo (2013) from Ogoni Kingdom in Rivers State also but is lower than $100 \%$ reported by Sowemimo \& Oluwafemi (2017) in Osun State from same animal hosts. This observation could be attributed to existing environmental and ecological factors between these locations.

This investigation has shown that of the two communities (Oba-Ama and Ogoloma-Ama) in Okrika, Ogoloma-Ama had the highest prevalenve and mean infection rate with an average of $18.02 \pm 17.2$ parasites per lizard and a prevalence of $84.8 \%$ while Oba Ama had a mean infection of $13.36 \pm 16.2$ per lizard and a prevalence of $76.3 \%$. This could be due to the settlement types; Ogoloma-Ama is a more urbanized area with high anthropogenic activities in addition with the release of so much petroleum pollutants. Pollutants pose some sub lethal physiological stress to hosts thereby reducing their capacity to withstand parasite invasion which results into increasing infection levels (Koprivnikar et al., 2007) as against Oba-Ama which still maintains its pure vegetation with less human activities around.

Nematodes had a prevalence of $67.1 \%$, cestodes $26.7 \%$ and trematodes $6.2 \%$. This shows that the most prevalent helminth taxa recovered from the lizard A. agama examined were the 
nematodes, especially $S$. brevicaudata. Similar findings have previously been reported in Nigeria and other parts of the world. Four of the seven helminths recovered from A. agama in Lagos State, Nigeria (Adeoye \& Ogunbanwo, 2007) and 3 of the 4 helminthes parasites reported from Nsugbe, Anambra State, Nigeria (Nwadike \& Ilozumba, 2010) were nematodes with $S$. brevicaudata the most abundant. The rich diversity of nematodes in the agamid lizard and other previous reports could be due to the fact that they exhibit a direct life cycle (Albarwari \& Saeed, 2007). On the other hand, it also shows that $S$. Brevicaudata is a major parasite of the Agamid lizards.

Trematodes in this study had a low prevalence of $6.2 \%$ which is higher than the prevalence of trematodes from other studies in Nigeria such as Adeoye \& Ogunbanwo (2007) who recorded a prevalence of $1.6 \%$, while Sowemimo and Oluwafemi (2017) had 1.5\%. Generally, the low prevalence of trematodes in this and other studies in Nigeria and other countries (Glalaktionov \& Dobrovolsky, 1998) could be as a result of the inability of the trematode larval stages to locate their intermediate hosts, and could also be due to the diet preference of the agamid lizard which may not include some trematode intermediate hosts. The few reported trematodes in agamids are basically members of the Genus Mesocoelium (M. monas and M. monodi). This study recovered different unidentified species of Mesocoelium which could not be seen as the conventional species due to morphological differences such shape, positions of the testes and lenght of the body.

Oochoristica sp. was the only cestode encountered in this study. This cestode differs morphologically from the previously reported Oochoristica species (Zazoo, 2013; Adeoye \& Ogunbanwo, 2007; Sowemimo \& Oluwafemi, 2017; Nwandike \& Ilozumba, 2017; Goldberg $\&$ Bursey, 2001). This species was previously encountered by Aisien \& Igetei (2018) in their study on some anurans from southern Nigeria and shows same features such as sizes of mature proglottids, shape and arrangements of the testes and presence of a neck which is in direct contrast with the previously reported Oochoristica species. This observation does not only shows increase in the Oochoristica species and wide geographical ranges but also indicate its presence as not accidental (Aisien \& Igetei, 2018). Moreso, the presence of members of the genus Oochoristica in anurans and agamids suggest there could be a relationship in diet selections of both host groups.

In this study, males were more associated with parasitic helminth infections than the females. This is in agreement with the reports of Adeoye \& Ogunbanwo (2007). Sulieman et al. (2019) also recoreded a higher prevalence of helminths in the male white-spotted geckos in Sudan. This trend could be because the males are more active and cover more grounds during foraging which exposes them to more parasites. In contrast, Omonona et al. (2011) reported female agamids to be more infected. Nwadike \& Ilozumba (2010) and Sowemimo \& Oluwafemi (2017) recorded no significant differences in prevalence of infections between gender. Amo et al. (2005) observed that females and males showed similar susceptibility to parasite infections. These authors attributed this to the similar diet composition of both sexes exposing them to equal chances of infection. Some other studies on lizards and other organisms have shown male hosts to be more prone to parasite infections (Uller \& Olsson, 2003) which they linked to the immune suppressive effects of the male hormone (testosterone) during reproductive periods (Roberts et al., 2004). Secondly, in our own view, another reason for sex dependent parasitism of helminths could be due to size. Morphologically, a large body mass provides the parasite an abundance of desired nutrients, resources needed for colonization and survival i.e space to feed and reproduce (Aho, 1990; Van sluys et al., 1994; Poulin, 1997). Robert et al., (2020) in a correlation study on the

ISSN 2721-1304 (Print), ISSN 2721-1207 (online)

Copyright @ 2020, Journal La Lifesci, Under the license CC BY-SA 4.0 
agamid lizards in Rivers State, Nigeria reported a significant positive correlation between parasite prevalence and some morphometric measurements. This could be the case of the rainbow lizard (A. Agama) as the adult males are larger than the females (Harris, 1963).

The rectum harboured two nematodes (Strongyluris brevicaudata and Parapharyngodon awokoyai) and a trematode (Mesoceolium spp). This showed the rectum to be the most preffered microhabitat for parasite infections from both locations. This agrees with those of Adeoye \& Ogunbanwo (2007), Nwadike \& Ilozumba (2010) and Sowemimo \& Oluwafemi (2017) where the rectum was also reported to be the predilection site for Strongyluris brevicaudata and Parapharyngodon awokoyai. Helminths seek out places in their hosts that could provide máximum nutritional and survivability. The rectum in the A. agama has a larger lumen than most parts of the gut, it contains enormous amount of undigested food which could be beneficial to these nematodes who have functional digestive systems. Also the rectum devoid of the high peristaltic movement seems safer for nematodes who are slow in movement and lack serious adhering structures. The small intestine hosted a single cestode (Oochoristica sp.) and some Strongyluris brevicaudata. Cestodes generally lack digestive systems and will always inhabit the small intestine of vertebrates which is a region rich with soluble nutrients and good for absorption (Jennings, 1997). Encysted Ascaridean larva was only recovered from the body cavity of the agamid lizard which serves as its paratenic host. The presence of this larval stage shows that there is a feeding relationship between members of the herpetofauna. Some anurans also serve as paratenic hosts to this larvae whose definitive hosts are snakes (Imasuen et al., 2012).

\section{Conclusion}

In all, the present study has established the endohelminth fauna of A. agama in OgolomaAma and Oba-Ama of Okrika, Rivers State, Nigeria. The helminths included Strongyluris brevicaudata, Parapharyngodon awokoyai, encysted Ascaridida larva (Nematoda); Oochoristica sp (Cestoda) and Mesoceolium spp. (Trematoda). More interesting is the incidence of different species of Mesocoelium and a single species Oochoristica which was quite different from the ones previously reported in A. agama by other authors in Nigeria and other parts of the world.

\section{References}

Adeoye, G.O \& Ogunbanwo, O.O (2007). Helminth parasites of the African Lizard Agaman agama (Squamata: Agamidae), in Lagos, Nigeria. Revista de Biological Tropical, 55: 417-425.

Aho, J.M (1990). Helminth communities of amphibians and reptiles: comparative approaches to understanding pattern and process.157-195.DOI 10.1007/978-94-009-0837-67.

Aisien, M.S.O. \& Igetei, J. E. (2018).Oochristica infection in anurans (Sclerophrys maculatus and Ptychadena oxyrhynchus) from Southern Nigeria. Herpetology Notes, 11, 901905.

Al-Barwari, S. E. and Saeed, I. (2007). On the helminth fauna of some Iraqi reptiles. Turkey Journal of Parasitology, 31: 330 - 336

Amadi, N., Robert, B., Chukwu, H.O., Dendi, D., Amuzie, C.C., Meek, R. and Luiselli, L.(2020). Life in the suburbs: artificial heat source selection for nocturnal thermoregulation in a diurnally active tropical lizard, Web Ecology. 20, 161-172.

Ameh I.G \& Ajayi, J.A (1996). A gregarian parasite of the wall gecko. Nigerian Journal of 
Parasitology, 17: 121-123.

Amo, L., Fargallo, J.A., Martinez-Padilla, J., Millán, P. L \& Martin, J. (2005). Prevalence and intensity of blood and intestinal parasites in a field population of a Mediterranean lizard.

Anderson, R. M. \& Gordon, D. M. (2009). Processes influencing the distribution of parasite numbers within host populations with special emphasis on parasite-induced host mortalities. Parasitology, 85, 373.https://doi.org/10.1017/S0031182000055347PubMed

Babero, B. B \& Okpala, I (1962). Parasites of the Lizard, Agama colonarum in Nigeria with description of new species. Transactions of American Microscopical Society,81: 6162.

Bennett, D. (1998). Monitor Lizards, Natural History, Biology and Husbandry. Frankfurt Germany: Edition Chimaira.

Galaktionov, K.V. and Dobrovolsky, A .A. (1998). The origin and evolution of the life cycles of trematodes. Petersburg: Science, 403.

Goldberg, S.R. and Bursey, C. R. (2001). Intestinal helminths of four species of skinks(Mabuya)(Sauria : Scincidae) from South Africa. Journal of Veterinary Research, 68: 143-147.

Harris, V.A. (1963). The Anatomy of the rainbow lizard. London, England: Hutchinson Tropical Monographs.

Imasuen, A.A., Enabulele, E.E. and Aisien, M.S.O. (2012). Helminth community of tree frogs at the Okomu National Park, Edo State, Nigeria. Nigerian Journal of Parasitology, 33: 1-8.

Koprivnikar, J., Forbes, M.R. \& Baker, R.L. (2007). Contaminant effects on host-parasite interactions: Atrazine, frogs, and trematodes. Environmental Toxicology and Chemistry; 26: 2166-2170.

Nash, H. (2005). Life cycles, symptoms, diagnosis and treatment of pentastomes in reptiles: Respiratory Parasites. Veterinary Services Department, Drs. Foster \& Smith Inc.

Nwadike, C. C. and Ilozumba, P. C. O. (2015). Helminth Endoparasites of the Rainbow Lizard, Agama agama (Squamata: Agamidae) in Nsugbe, Anambra State, Nigeria. The Zoologist, 13: 22 - 27.

Omonona, A.O., Adedokun, O.A \& Adekoya-Gafaar, S.A (2011). Parasitological Studies on Agama Lizard (Agama agama) in Ibadan. Advanced Environmental Biology, 5: 803807.

Poulin, R (1997). Species richness of parasite assemblages: evolution and patterns. Annual Research in Ecological System 28(1): 341-358.

Robert, B. Ugbomeh, A.P. and Amuzie, C.C. (2020).Correlations of body weight and snoutvent length to parasite burden in agama agama of Ogoloma Ama and Oba Ama, Okrika, Rivers State, Nigeria. African Journal of Biology and Medical Research, 3(1): 1-8.

Roberts, M.L., Buchanan, K. \& Evans, M. (2004). Testing the immune competence-handicap 
hypothesis: a review of evidence. Journal of Animal Behaviour, 68: 227-239.

Schmidt, G.D (1986). Handbook of Tapeworm Identification. Boca Raton, Florida CRC Press.

Smyth, J.D. 1994. Cambridge University Press, London. Animal Parasitology $3^{\text {rd }}$ edition.

Sowemimo, O.A \& Oluwafemi, T.A. (2017). A Survey of Helminth Parasites of the Lizard, Agama agama in Ile-Ife and Ibadan Southwest Nigeria. Journal of Bacteriology and Parasitology, 8, 303. doi:10.4172/2155-9597.1000303.

Sulieman, Y., Eltayeb, R. E., Srimek, N. and Pengsakul, T. (2019). Helminth parasites of the white-spotted wall gecko, Tarentola annularis (Squamata: Gekkonidae), from Shendi area, Sudan. Annals of Parasitology, 65(1):71-75.

Uller, T. \& Olsson, M. (2003). Prenatal exposure to testosterone increases ectoparasite susceptibility in the common lizard (Lacerta vivipara).Proceedings of the Royal Society of London, 270: 1867-1870.

Van Sluys, M., Rocha, C.F. D \& Ribas, S.C (1994). Nematodes infecting the lizard Tropidurus itambere in Southeastern Brazil. Amphibia-Reptilia, 15(4): 405-408.

Wekhe, S. N \& Olayinka, F.O. (1999). The role of Agama agama in the transmission of coccidiosis in poultry. Nigerian Vetenary Journal, 20: $34-36$.

Yamaguti, S (1958). The Digenetic Trematodes of Vertebrates. New York Interscience Publishers. Systema Helminthum. Vol 1.

Yamaguti, S. (1961). Systema helminthum. The nematodes of vertebrates. Volume III, 679 Interscience Publishers, New York.

Zaazoo, L (2013). Helminth Parasites of the Common Lizard (Agama agama) in three Communities in Gokana Local Government Area, Rivers State. B.Sc. Dissertation to the Department of Animal and Environmental Biology, Rivers State University, Port Harcourt, Nigeria. 